\title{
Hypothermia or normothermia after cardiac arrest? Do not throw the baby out with the bath water?
}

\author{
Said Hachimi-Idrissi • Joline Goossens • \\ Arthur Raymond Hubert van Zanten
}

Received: 19 July 2014/Accepted: 7 August 2014/Published online: 28 August 2014

(C) SIMI 2014

This idiomatic expression illustrates what is now potentially happening with respect to targeted temperature management (TTM) after Nielsen and coworkers [1] published their recent landmark paper, demonstrating that in patients after cardiac arrest, normothermia confers similar effects on outcome compared to mild therapeutic hypothermia.

We should not discard something valuable in our eagerness to get rid of something useless associated with it. In our countries, as well as in various parts of the world, colleagues are now questioning the conventional TTM, defined as an intentional reduction of the body temperature to $33-34{ }^{\circ} \mathrm{C}$ after out-of-hospital cardiac arrest (CA) [2].

From a scientific perspective, questioning TTM is legitimate, but going back to the pre-cooling era may be dangerous, and may even pose devastating risks affecting the neurological outcome of patients who initially survive CA $[3,4]$.

A growing number of patients are surviving CA without increase in the rate of neurologic disability [5]. Over a 10 -year period, the percentage of survivors has increased from 13.7 to $22.4 \%$, while the rate of clinically significant neurological impairment has declined from 32.9 to $28.1 \%$

\footnotetext{
S. Hachimi-Idrissi $(\square) \cdot$ J. Goossens

Emergency Department, University Hospital of Ghent,

De Pintelaan 185, 9000 Ghent, Belgium

e-mail: said.hachimiidrissi@uzgent.be

J. Goossens

e-mail: joline.goossens@uzgent.be
}

\section{A. R. H. van Zanten}

Department of Intensive Care, Gelderse Vallei Hospital,

Willy Brandtlaan 10, 6716 RP Ede, The Netherlands

e-mail: zantena@zgv.nl
[5]. These results are encouraging. However, we still do not know which factors influence this sequence of ongoing improvements in neurological outcomes after return of spontaneous circulation (ROSC)?

Among the latest important changes in CA treatment is the application of high-quality chest compressions without interruptions that seems to increase the chance of CA survival $[6,7]$. Other changes that have occurred over the past few decades include: quality-improvement efforts in the recognition of $\mathrm{CA}$, and the institution of appropriate resuscitation manoeuvres, as well as the importance of timely defibrillation for patients in ventricular fibrillation (VF) or ventricular tachycardia (VT). In addition to these measures, post-resuscitation care has improved markedly. Some reports on CA suggest that cooling may be beneficial in terms of reducing the risk of neurological complications [8].

Indeed, cooling or mild therapeutic hypothermia (MTH) is based on extensive laboratory evidence and clinical studies that highlight the beneficial effect of cooling to a core temperature of $33-34{ }^{\circ} \mathrm{C}$ to secondarily mitigate brain damage, and hence to improve the neurological outcome [9-11].

It is thought that therapeutic hypothermia can affect and simultaneously block multiple metabolic pathways, inflammatory reactions and apoptosis processes that occur after an ischemic cascade [12].

Consequently the European Resuscitation Council (ERC) recommends "that patients achieving ROSC after VT/VT should be cooled down to $33-34{ }^{\circ} \mathrm{C}$ for a period of 12-24 h" [13]. In contrast, the recent Nielsen TTM trial concludes that normothermia is equivocal to hypothermia, and this may lead to misinterpretations and assumptions that no cooling is recommended, and that we should abandon cooling [1]. 
What are reasons for the divergent outcomes of the three major clinical TTM trials resulting in different conclusions $[1,3,4]$ ? Probably the answers are in the details.

The Nielsen TTM trial does not assess the same hypothesis as the two previous TTM trials did. In more detail, this study assessed the effects of MTH compared to TTM controlled at normothermia. However, the HACA [3] and Bernard [4] studies assessed cooling versus no cooling with a treatment group having a target temperature of $33-34{ }^{\circ} \mathrm{C}$ for a period of $12-24 \mathrm{~h}$, while in the control group temperature was not controlled (the current temperature management at that time). The normothermia groups in these studies achieved an average normothermia temperature of 37.6 , and $37.3{ }^{\circ} \mathrm{C}$, respectively. However, in the Nielsen trial, the control group was also a TTM group keeping the normothermia group meticulously at $36{ }^{\circ} \mathrm{C}$. These $1.3-1.6^{\circ} \mathrm{C}$ differences in temperature compared to the Bernard and the HACA studies should be interpreted as relevant, and may be an explanation for differences in effects among TTM studies [14, 15]. Thus the "normothermia group" in the Nielsen TTM trial in fact is a TTM group, with body temperature targets purposely, rigorously and actively kept at $36{ }^{\circ} \mathrm{C}$. Moreover, the methods section in Nielsen TTM trial suggests that all patients were evaluated, but this seems questionable: 1,431 patients were screened, and 939 were enrolled; that is an unusually high enrolment rate of $66 \%$. The study took place in 36 intensive care units in just over 2 years, and this translates to 19 patients screened and 13 enrolled per centre per year (1 patient per centre per month). This number seems extremely low.

Another striking factor is the percentage of bystander CPR, which is $74 \%$ in this study. In contrast, in the HACA or the Bernard studies the percentages observed were only 43 and $49 \%$, respectively. Moreover the standard of care in participating hospitals in the Nielsen TTM trial was MTH, and the default option for patients not enrolled in the trial was hypothermia.

Another potential difference is the active re-warming from 33 to $36{ }^{\circ} \mathrm{C}$ over a 6-h period in the hypothermia arm of the study, which was faster than in the previous studies as well as advised by others $[3,4,16,17]$. There was also a greater incidence of spontaneous hypothermia (before start of active cooling) in the $33{ }^{\circ} \mathrm{C}$ group, potentially indicating greater severity of brain injury with a diminished shivering response. There were more seizures in the $33{ }^{\circ} \mathrm{C}$ group, in spite of the well-recognized anti-seizure effects of hypothermia. Finally, more patients in the $33{ }^{\circ} \mathrm{C}$ group were withdrawn from studies because of greater severity of injury.

In the Nielsen TTM trial [1], the outcome was unequivocal meaning: no difference in outcome, neither benefits nor harm between the study arms suggesting that normothermia is as good as the MTH strategies applied in previous studies [3, 4]. Moreover, based on the current technology and the other clinical factors, we are unable to select those patients who have a significant post arrest encephalopathy, and those without such consequences, thereby missing the chance to modify the neurological injury in the acute care of those post-cardiac arrest patients who could potentially benefit from hypothermia. After CA, we may encounter at least three different types of patients achieving ROSC: first, the futile group in which all further therapeutic measures will eventually not improve the neurological outcome (too long arrest time, long resuscitation effort and high incidence or co-morbidity,) second a minimally neurologically injured group of patients in whom TTM hypothermia or TTM normothermia probably would not modulate outcome, and third, a group of moderate neurologically injured patients in whom TTM should be mandatory. The differences in outcome are at least in part due to these underlying medical conditions, such as the time of no perfusion, and the state of low perfusion, i.e. the quality of CPR as well as the post cardiac arrest care. In the TTM trial by Nielsen and coworkers [1], the studied patients had a median ROSC time of $25 \mathrm{~min}$, with a wide interquartile range varying from 16 to $40 \mathrm{~min}$. In those patients with prolonged time to ROSC, we would not expect that TTM at temperature targets of $33-34{ }^{\circ} \mathrm{C}$ or even other therapeutic measures, would markedly improve the neurologic outcome, due to the probably already present brain damage.

Furthermore, the neurologic evaluation in the TTM trial [1] was based on the Cerebral Performance Category and the modified Rankin scales, which are rather simple tests with which to assess patients' independent daily living performance, and may be considered inadequate for assessing cognitive impairment in survivors of CA $[18,19]$. Moreover, several small differences between both groups (the $33{ }^{\circ} \mathrm{C}$ versus the $36^{\circ} \mathrm{C}$ ) such as differences in inadequate organ perfusion frequency, time to randomization, as well as sedation used and the post-cardiac management were all noted. All these differences, although minor, may have accounted for the lack of benefit of TTM at lower temperatures when accumulated.

Although a recent high-quality study provides evidence to abandon TTM at temperatures of $32-34{ }^{\circ} \mathrm{C}$ as it showed to be as effective as TTM at $36{ }^{\circ} \mathrm{C}$, we believe the debate will go on for some time. More importantly, this illustrates the need for careful testing and evaluation of each individual component of patients' management in critical care, to be certain that our current practice is not only evidencebased, but that it is actually based on evidence that is derived from adequate testing of appropriate options. We reiterate that the Nielsen TTM trial, as such, is a "DOSE" finding study, not a comparison between cooling and not 
cooling. We believe TTM is pivotal and prevention of fever essential.

In conclusion, there will be believers and non-believers of TTM at $32-34{ }^{\circ} \mathrm{C}$, but for the non-believers please do not throw the baby out with the bath water. Controlling the temperature is the best option even while questioning whether $33-34{ }^{\circ} \mathrm{C}$ or $36{ }^{\circ} \mathrm{C}$ is the optimal therapeutic level.

Conflict of interest None.

\section{References}

1. Nielsen N, Wetterslev J, Cronberg T, Erlinge D, Gasche Y, Hassager C, Horn J, Hovdenes J, Kjaergaard J, Kuiper M, Pellis T, Stammet P, Wanscher M, Wise MP, Aneman A, Al-Subaie N, Boesgaard S, Bro-Jeppesen J, Brunetti I, Bugge JF, Hingston CD, Juffermans NP, Koopmans M, Køber L, Langørgen J, Lilja G, Møller JE, Rundgren M, Rylander C, Smid O, Werer C, Winkel P, Friberg H, TTM Trial Investigators (2013) Targeted temperature management at $33^{\circ} \mathrm{C}$ versus $36^{\circ} \mathrm{C}$ after cardiac arrest. N Engl J Med 369:2197-2206. doi:10.1056/NEJMoa1310519

2. Nunnally ME, Jaeschke R, Bellingan GJ, Lacroix J, Mourvillier B, Rodriguez-Vega GM, Rubertsson S, Vassilakopoulos T, Weinert C, Zanotti-Cavazzoni S, Buchman TG (2011) Targeted temperature management in critical care: a report and recommendations from five professional societies. Crit Care Med 39(5):1113-1125. doi:10.1097/CCM.0b013e318206bab2

3. Hypothermia after Cardiac Arrest Study Group (2002) Mild therapeutic hypothermia to improve the neurologic outcome after cardiac arrest. N Engl J Med 346:549-556

4. Bernard SA, Gray TW, Buist MD, Jones BM, Silvester W, Gutteridge G, Smith K (2002) Treatment of comatose survivors of out-of-hospital cardiac arrest with induced hypothermia. N Engl J Med 346:557-563

5. Girotra S, Nallamothu BK, Spertus LA, Li Y, Krumholz HM, Chan PS, American Heart Association Get With the GuidelinesResuscitation Investigators (2012) Trends in survival after inhospital cardiac arrest. N Engl J Med 367:1912-1920. doi:10. 1056/NEJMoa1109148

6. Idris AH, Guffey D, Aufderheide TP, Brown S, Morrison LJ, Nichols P, Powell J, Daya M, Bigham BL, Atkins DL, Berg R, Davis D, Stiell I, Sopko G, Nichol G, Resuscitation Outcomes Consortium (ROC) Investigators (2012) Relationship between chest compression rates and outcomes from cardiac arrest. Circulation 125:3004-3012. doi:10.1161/CIRCULATIONAHA.111. 059535

7. Stiell IG, Brown SP, Christenson J, Cheskes S, Nichol G, Powell J, Bigham B, Morrison LJ, Larsen J, Hess E, Vaillancourt C, Davis DP, Callaway CW, Resuscitation Outcomes Consortium (ROC) Investigators (2012) What is the role of chest compression depth during out-of-hospital cardiac arrest resuscitation? Crit Care Med 40:1192-1198. doi:10.1097/CCM.0b013e31823bc8bb

8. Morrison LJ, Deakin CD, Morley PT, Callaway CW, Kerber RE, Kronick SL, Lavonas EJ, Link MS, Neumar RW, Otto CW, Parr
M, Shuster M, Sunde K, Peberdy MA, Tang W, Hoek TL, Böttiger BW, Drajer S, Lim SH, Nolan JP, Advanced Life Support Chapter Collaborators (2010) Part 8: advanced life support: 2010 international consensus on cardiopulmonary resuscitation and emergency cardiovascular care science with treatment recommendations. Circulation 122 Suppl 2(16):S345-S421. doi:10. 1161/CIRCULATIONAHA.110.971051

9. Zhao H, Steinberg GK, Sapolsky RM (2007) General versus specific actions of mild-moderate hypothermia in attenuating cerebral ischemic damage. J Cereb Blood Flow Metab 27(12):1879-1894

10. Arrich J, Holzer M, Havel C, Müllner M, Herkner H (2012) Hypothermia for neuroprotection in adults after cardiopulmonary resuscitation. Cochrane Database Syst Rev 12(9):CD004128. doi:10.1002/14651858.CD004128.pub3

11. Holzer M, Bernard SA, Hachimi-Idrissi S, Roine RO, Sterz F, Müllner M (2005) Collaborative Group on Induced Hypothermia for Neuroprotection After Cardiac Arrest: hypothermia for neuroprotection after cardiac arrest: systematic review and individual patient data meta-analysis. Crit Care Med 33:414-418

12. González-Ibarra FP, Varon J, López-Meza EG (2011) Therapeutic hypothermia: critical review of the molecular mechanisms of action. Front Neurol 2:4. doi:10.3389/fneur.2011.00004. eCollection

13. Nolan JP, Morley PT, Hoek TL, Hickey RW, Advancement Life support Task Force of the International Liaison committee on Resuscitation (2003) Therapeutic hypothermia after cardiac arrest. An advisory statement by the Advancement Life support Task Force of the International Liaison committee on Resuscitation. Resuscitation 57(3):231-235

14. Kuboyama K, Safar P, Radovsky A, Tisherman SA, Stezoski SW, Alexander H (1993) Delay in cooling negates the beneficial effect of mild resuscitative cerebral hypothermia after cardiac arrest in dogs: a prospective, randomized study. Crit Care Med 21:1348-1358

15. Grigore AM, Grocott HP, Mathew JP, Phillips-Bute B, Stanley TO, Butler A, Landolfo KP, Reves JG, Blumenthal JA, Newman MF, Neurologic Outcome Research Group of the Duke Heart Center (2002) The rewarming rate and increased peak temperature alter neurocognitive outcome after cardiac surgery. Anesth Analg 94(1):4-10

16. Polderman KH (2009) Therapeutic hypothermia and controlled normothermia in the intensive care unit: practical considerations, side effects, and cooling methods. Crit Care Med 37:1101-1120. doi:10.1097/CCM.0b013e3181962ad5

17. Holzer M (2010) Targeted temperature management for comatose survivors of cardiac arrest. N Engl J Med 363(13):1256-1264. doi:10.1056/NEJMct1002402

18. Fugate JE, Moore SA, Knopman DS, Claassen DO, Wijdicks EF, White RD, Rabinstein AA (2013) Cognitive outcomes of patients undergoing therapeutic hypothermia after cardiac arrest. Neurology 81(1):40-45. doi:10.1212/WNL.0b013e318297ee7e

19. Cronberg T, Lilja G, Rundgren M, Friberg H, Widner H (2009) Long-term neurological outcome after cardiac arrest and therapeutic hypothermia. Resuscitation 80(10):1119-1123. doi:10. 1016/j.resuscitation.2009.06.021 